\title{
Feasibility of diagnosis of postcardiotomy tamponade by miniaturized transesophageal echocardiography.
}

\author{
Hitoshi Hirose, MD \\ Thomas Jefferson University \\ Shreya Gupta, BS \\ Thomas Jefferson University \\ Harrsion Pitcher, MD \\ Thomas Jefferson University \\ Joseph Miessau, MS \\ Thomas Jefferson University \\ Poiph Yang and Additional works at: https://jdc.jefferson.edu/surgeryfp \\ Thomas Jefferson University \\ Part of the Surgery Commons

\section{Let us know how access to this document benefits you} \\ See next page for additional authors
}

\section{Recommended Citation}

Hirose, MD, Hitoshi; Gupta, BS, Shreya; Pitcher, MD, Harrsion; Miessau, MS, Joseph; Yang, MD, Qiong; Yang, MD, Jenny; and Cavarhocchi, MD, Nicholas, "Feasibility of diagnosis of postcardiotomy tamponade by miniaturized transesophageal echocardiography." (2014).

Department of Surgery Faculty Papers. Paper 116.

https://jdc.jefferson.edu/surgeryfp/116

This Article is brought to you for free and open access by the Jefferson Digital Commons. The Jefferson Digital Commons is a service of Thomas Jefferson University's Center for Teaching and Learning (CTL). The Commons is a showcase for Jefferson books and journals, peer-reviewed scholarly publications, unique historical collections from the University archives, and teaching tools. The Jefferson Digital Commons allows researchers and interested readers anywhere in the world to learn about and keep up to date with Jefferson scholarship. This article has been accepted for inclusion in Department of Surgery Faculty Papers by an authorized administrator of the Jefferson Digital Commons. For more information, please contact: JeffersonDigitalCommons@jefferson.edu. 


\section{Authors}

Hitoshi Hirose, MD; Shreya Gupta, BS; Harrsion Pitcher, MD; Joseph Miessau, MS; Qiong Yang, MD; Jenny Yang, MD; and Nicholas Cavarhocchi, MD 
As submitted to:

The Journal of surgical research.

And later published as:

Feasibility of diagnosis of post- cardiotomy tamponade by miniaturized transesophageal echocardiography.

Volume 190, Issue 1, pages: 276-279, July 2014

DOI: $10.1016 / j . j s s .2014 .02 .039$

Hitoshi Hirose, MD; Shreya Gupta, BS; Joseph Miessau, MS; Harrison Pitcher, MD; Qiong Yang, MD; Nicholas Cavarocchi, MD.

From Department of Surgery, Thomas Jefferson University Hospital, Philadelphia, PA.

Running title: hTEE probe to diagnose pericardial tamponade

Keywords: Echocardiography; tamponade; cardiac surgery; diagnosis.

Corresponding Author: Hitoshi Hirose, MD.

1025 Walnut Street, Suite 605, Philadelphia, PA, 19107 USA

Telephone: 215-518-4418; Fax: 215-955-6010; E-mail: genex@ nifty.com

This paper was presented at Academic Surgical Congress 2014, San Diego.

Author's contributions:

Shreya Gupta: writing the article, data collection, analysis and interpretation.

Joseph Miessau, Harrison Pitcher, and Qiong Yang: data collection. 
Nicholas Cavarocchi: conception and design, critical revision of the article.

Hitoshi Hirose: conception and design, data collection, analysis and interpretation, critical revision of the article.

The authors report no proprietary or commercial interest in any product mentioned or concept discussed in this article

Word count: 1637 


\begin{abstract}
Introduction: Pericardial tamponade after cardiac surgery is a critical diagnosis that can be difficult to diagnose using conventional cardiac monitoring. Transesophageal echocardiography can provide comprehensive information to make the diagnosis but is not always available, whereas a transthoracic echocardiography has its utility limited because of the body habitus or other surgical effects. New monitoring devices, miniaturized hemodynamic transesophageal echocardiography (hTEE), which allows point of care assessment of cardiac filling and functions, may aid in diagnosis of post-cardiotomy tamponade.
\end{abstract}

Methods: From May 2011 to July 2013, 21 patients underwent hTEE to rule out pericardial tamponade for clinical suspicion of tamponade following open-heart surgery. The hTEE images were reviewed and the patient outcomes were analyzed.

Results: Nine patients showed no evidence of pericardial collection and did not require reexploration. Two patients showed a presence of small hematoma without ventricular compression, and also did not undergo exploration. Ten patients were positive for pericardial tamponade (effusion or hematoma with ventricular compression); 8 of these cases underwent emergent surgical exploration. Of the 2 patients who did not undergo immediate re-operation, one was managed by chest tube manipulation; the other patient underwent subsequent surgical exploration after his extensive coagulopathy was corrected by medical treatment.

Conclusions: The diagnosis of pericardial tamponade post cardiotomy is feasible using a disposable hTEE based on our limited experience. We avoided unnecessary explorations while concomitantly made prompt diagnosis in emergent situations. The hTEE device was a valuable tool in hemodynamic management in the intensive care unit, allowing rapid evaluations. Word Count of abstract: $247(\max 250)$ 


\section{Introduction}

Post-operative cardiac surgery patients require extensive hemodynamic monitoring for potential life-threatening complications, pericardial tamponade being one of them. Postoperative pericardial tamponade requires expedient diagnosis and management to prevent unfavorable outcomes. The typical signs of pericardial tamponade are hypotension, low cardiac output, elevated filling pressure, and equalization of right-sided cardiac pressures on hemodynamics monitoring. If a patient develops obvious sings of tamponade after cardiac surgery, they need to undergo an emergent mediastinal exploration without any further imaging study. Any delay in reexploration can lead into fatal and non-fatal complications. ${ }^{1,2}$ However, the diagnosis of pericardial tamponade is not always easy and sometimes requires additional imaging studies. Emergent explorations without definitive diagnosis may increase the number of negative explorations and increase the utilization of hospital resources substantially. Moreover, reexploration of the sternum, even if negative, increases mortality, morbidity and length of stay. ${ }^{3}$ Thus, it is important to have a clear indication of when surgical exploration is necessary and when not.

The standard imaging study to diagnose pericardial tamponade is transesophageal echocardiography (TEE), which provides comprehensive information about the pericardial space, ventricular volume and function. TEE requires equipment and qualified personnel to perform the study; thus it often limits the use of TEE in an intensive care unit (ICU) especially during offhours and emergent situations. Transthoracic echocardiography may be more easily accessible in the ICU; however it may not be able to provide enough information to diagnose pericardial tamponade due to body habitus, surgical tubes, edema from surgery, and/or mechanical ventilation. 
Recently, FDA approved a disposable miniaturized (pro b e size $5.5 \mathrm{~mm}$ diameter) hemodynamic transesophageal echocardiography (hTEE, Imacor, Garden City, NY). This device has been used for the management of critically ill patients in ICU. Trained intensivists can insert and interpret hTEE finding for clinical decision-making. This probe provides focused information of the cardiac filling and ventricular functions, ${ }^{4}$ which might be adequate to diagnose pericardial tamponade. In this study, we investigated the feasibility of the diagnosis of the pericardial tamponade by hTEE among early post-cardiac surgery patients.

\section{Methods}

From May 2011 through July 2013, a total of 584 patients were admitted to our surgical ICU after cardiac surgery (270 isolated coronary artery bypass graft [CABG], $52 \mathrm{CABG}$ with valve combined, 174 valve, 23 heart transplant, 29 ventricular assist device placement, 36 other cardiac procedures). HTEE probe was used for hemodynamic monitoring in addition to the conventional Swan-Ganz monitoring in high-risk patients. The hTEE was performed under mild sedation routinely after cardiac surgery without additional sedation or paralysis while the patients were still intubated. The hTEE images were performed and read by the trained intensivists without consulting cardiology or radiology. Their training included didactic lectures, mannequin training and hands-on experience with patients with trained personnel. The probe was removed after each study unless continuous monitoring was required. The diagnoses were made based on the image results with other hemodynamic data and appropriate intervention was initiated at the time of the hTEE.

Institutional Review Board approved retrospective study of hTEE imaging. The images stored in the console were retrieved and medical records were reviewed to identify the hTEE studies performed to rule out early pericardial tamponade within 72 hours after surgery. The 
patient demographics and hemodynamic parameters were also obtained from the medical record. During the study period, hTEE imaging was performed on 129 patients for various indications. Out of the 129 patients, 21 patients underwent hTEE to rule out pericardial tamponade with a high clinical suspicion of early postoperative tamponade, which included unexplained hypotension, elevated filling pressures, and low cardiac output.

Positive tamponade finding was defined as the presence of a pericardial collection (effusion or hematoma) compressing the ventricle. Negative finding was defined as no pericardial collection. If there was a pericardial collection but no ventricular compression, the case was individually evaluated by the intensivists and surgical team.

The patients who had hTEE done to rule out pericardial tamponade were divided into two groups: with or without tamponade based on hTEE. Cardiac parameters and chest tube output 4 hours prior to hTEE study were compared between the two groups. The end-point of this study was surgical exploration performed during the same admission period from the primary surgery. In addition to that, the hospital survivals in these patients who were suspected for tamponade was studied. Statistical comparisons between the two groups were performed using chi-square test or Fisher exact test for categorical variables, and student t-test for continuous variables. P-values less than 0.05 were considered to be significant.

\section{Results}

The hTEE examinations were performed in 21 patients to rule out the clinical suspicion of pericardial tamponade. The trigger event for performing hTEE was hemodynamic instability (low cardiac output, elevated central venous pressure, and hypotension) without appropriate explanation in 18 patients and unexplained high chest tube output in 3 patients. The demographics of these patients were 17 males and 4 females, with a mean age of 61 years \pm 15 
years (Table 1). The primary surgical procedures were coronary artery bypass or/and valve $(n=9)$, heart transplant $(n=3)$, type A dissection $(n=6)$, ventricular assist device placement $(n=2)$ and ventricular septal defect repair $(n=1)$.

In 9 patients (43\%), hTEE was negative for pericardial effusion and diagnosis of tamponade was ruled out. These patients were further worked up for others entities on the differential diagnosis such as hypovolemia $(\mathrm{n}=5)$, right ventricular failure $(\mathrm{n}=2)$, and biventricular failure $(n=2)$. All patients were medically managed and no patient was taken to the operating room for re-exploration.

10 patients (48\%) were positive for pericardial tamponade (hematoma or effusion compressing the ventricle) based on hTEE imaging. These findings were discussed with the surgical team for consideration of surgical re-exploration. Among these 10 patients, 8 patients were immediately taken for surgical exploration and all 8 patients had positive exploration (pericardial tamponade). The other 2 positive patients were not taken for immediate operative intervention, but were rather managed medically. The first patient showed a large pericardial effusion with right ventricular compression, which was successfully drained by manipulation of the chest tubes. Continuous monitoring by hTEE on this patient after the manipulation of chest tubes was found to have no residual pericardial collection. The second patient with a positive hTEE study clearly demonstrated a tamponade, but was not explored initially because of the underlying extensive coagulopathy and the surgeon's preference. A repeat hTEE study was performed on the same patient a few hours later that showed tamponade; this prompted was surgical exploration. No patients required conventional TEE to confirm the diagnosis of pericardial tamponade before the exploration, although conventional TEE was performed by the anesthesiologist during the re-exploration in all patients. 
The remaining 2 patients showed a small hematoma or effusion without ventricular compression. These patients were medically managed and followed by serial hTEE. The repeat studies showed no increase in the size of the hematoma and preserved ventricular function. Thus, they did not require any surgical exploration.

During this study period, an additional 5 postoperative pericardial tamponade cases underwent surgical exploration without any hTEE or other imaging modalities. These 5 patients were diagnosed with pericardial tamponade shortly after arrival to the ICU based on the chest tube drainage and hemodynamics.

The hemodynamics data and chest tube output of the patients at the time of hTEE are shown in Table 2. There were no significant differences in terms of cardiac parameters and chest tube drainage between 2 groups. There was no hospital mortality in tamponade group and 2 deaths in the non-tamponade group. These postoperative mortalities were due to biventricular failure after heart transplantation (1) and stroke (1).

\section{Discussion}

Early postoperative pericardial tamponade after cardiac surgery requires prompt diagnosis and management. Untreated pericardial collection after cardiac surgery may quickly progress to unstable hemodynamics, cardiogenic shock and subsequent death. ${ }^{5}$ The incidence of the pericardial tamponade varies from $0.2 \%$ after coronary artery bypass grafting to $8.4 \%$ after heart transplants. ${ }^{6}$ The concern of developing post-surgical pericardial tamponade has been increasing in patients especially those on a new generation of antiplatelet agents and/or anticoagulants. ${ }^{7}$

For post-cardiotomy patients, conventional TEE serves as an imaging standard to confirm the diagnosis of tamponade. A TEE provides comprehensive information about the ventricular filling, function, valvular function, and pericardial space issues. ${ }^{8}$ Conventional TEE has been 
used intra-operatively during cardiac procedures and its real time images are used for weaning from cardiopulmonary bypass, adjustment of inotropes, and evaluation of the valve and ventricular functions in the operating room. However, in the ICU, the availability of conventional TEE has certain limitations due to availability of equipment, time, and qualified personnel. ${ }^{9}$ Although TEE is usually kept indwelled during cardiac surgery to monitor cardiac function for several hours, continuous TEE in ICU is not practical. Thus, a conventional TEE study in the ICU only offers a single "snapshot" at the time of study.

The hTEE consists of a slender probe almost the size of a nasogastric tube. Each probe is disposable and costs roughly $\$ 1250$. The placement of the hTEE probe does not require excessive anesthesia and the probe can be kept indwelling for maximum of 72 hours. The real time images help the intensivist make a decision and also allow the intensivist to assess the response to the treatment/interventions made.

In our retrospective review of hTEE images over the past 2 years in post-cardiac surgery patients, found that the diagnosis of early postcardiotomy pericardial tamponade provided by hTEE in conjunction with clinical findings was accurate. Those who were diagnosed with tamponade by hTEE had positive exploration and none had a negative exploration. Patients who were ruled out for tamponade by hTEE did not undergo any surgical explorations. In these patients, once other diagnoses were made by hTEE, treatment was initiated based on the findings. This study was limited due to the nature of the retrospective study and the data on the patients who underwent hTEE with suspicion of tamponade. Hemodynamic data may not reflect cardiogenic shock due to the minute-by-minute titration of the inotropes and vasopressor medications. More prospective studies in the future will help us determine whether this probe can 
be used as a part of a guideline to diagnose pericardial tamponade in this patient population with both sensitivity and specificity.

In conclusion, our retrospective study showed that the miniaturized hTEE probe is an efficient tool that can allow us to diagnose early pericardial tamponade in post-cardiotomy patients in timely fashion in conjunction with conventional monitoring. With hTEE, which is available in the intensive care unit and performed by intensivists, we may reduce resource utilization. 
Table 1: Summary of results

\begin{tabular}{|c|c|}
\hline Number of patients & 21 \\
\hline Mean age \pm standard deviation & $61 \pm 14.5$ years \\
\hline Sex & Male $=17$, Female $=4$ \\
\hline Primary surgery & $\begin{array}{l}\text { Coronary bypass } / \text { valve }=9 \\
\text { Heart transplant }=3 \\
\text { Type A dissection }=6 \\
\text { Ventricular assist device }=2 \\
\text { Others }=1\end{array}$ \\
\hline Trigger event & $\begin{array}{l}\text { Hemodynamic instability, shock }=18 \\
\text { Unexplainable high chest tube drainage }=3\end{array}$ \\
\hline Pericardial diagnosis by hTEE & $\begin{array}{l}\text { Tamponade }=10 \\
8 \text { went to surgery immediately. } \\
1 \text { went to surgery after medical management for } \\
\text { coagulopathy. } \\
1 \text { was managed by chest tube manipulation } \\
\text { Effusion without compression }=2 \text { (all medically managed) } \\
\text { Negative }=9 \text { (all patients did not require surgery) }\end{array}$ \\
\hline
\end{tabular}


Table 2: Hemodynamic parameters at the time of hTEE. Data were expressed mean \pm standard deviation or number with percentage.

\begin{tabular}{|l|c|c|c|}
\hline Diagnosis by hTEE & Tamponade & No tamponade & P-value \\
\hline Number of patients & $10(48 \%)$ & $* * 11(52 \%)$ & \\
\hline Number of inotropes and pressors * & $3.7 \pm 1.2$ & $3.4 \pm 1.2$ & .559 \\
\hline Mean systemic blood pressure $(\mathrm{mm} \mathrm{Hg})$ & $66 \pm 7$ & $73 \pm 15$ & .181 \\
\hline Pulmonary artery systolic pressure $(\mathrm{mm} \mathrm{Hg})$ & $36 \pm 6$ & $34 \pm 7$ & .489 \\
\hline Pulmonary artery diastolic pressure $(\mathrm{mm} \mathrm{Hg})$ & $19 \pm 5$ & $18 \pm 8$ & .723 \\
\hline Central venous pressure $(\mathrm{mm} \mathrm{Hg})$ & $12 \pm 4$ & $13 \pm 5$ & .617 \\
\hline Cardiac index (L/min/m2) & $2.1 \pm 0.4$ & $2.2 \pm 0.4$ & .574 \\
\hline Chest tube drainage 4hrs prior study (ml) & $426 \pm 74$ & $380 \pm 515$ & .772 \\
\hline Surgical exploration & $* * * 9(90 \%)$ & 0 & $<0.00001$ \\
\hline Survival to discharge & $10(100 \%)$ & $9(82 \%)$ & .156 \\
\hline
\end{tabular}

* Number of inotropes (epinephrine, milrinone, dobutamine), and pressors (phenylephrine, vasopressin, norepinephrine) was counted regardless the amount given to the patient due to rapid titration. ** No tamponade group includes 2 patients who had pericardial effusion without compression of the ventricle. $* * *$ One patient with pericardial effusion was successfully treated with chest tube management without surgical exploration. 


\section{References}

${ }^{1}$ Canadyova J, Zmeko D, Mokracek A. Re-exploration for bleeding or tamponade after cardiac operation. Interact Cardiovasc Thorac Surg 2012; 14:704-708.

2 Čanádyová J, Zmeko D, Mokráček A. Re-exploration for bleeding or tamponade after cardiac operation. Interact Cardiovasc Thorac Surg. 2012;14:704-7.

${ }^{3}$ Unsworth-White MJ, Herriot A, Valencia O, Poloniecki J, Smith EE, Murday AJ, Parker DJ, Treasure T. Resternotomy for bleeding after cardiac operation: a marker for increased morbidity and mortality. Ann Thorac Surg. 1995; 59:664-667.

${ }^{4}$ Hastings HM. Transesophageal echocardiography-guided hemodynamic assessment and management. ICU Director 2012; 3:38-41.

${ }^{5}$ Canadyova J, Zmeko D, Mokracek A. Re-exploration for bleeding or tamponade after cardiac operation. Interact Cardiovasc Thorac Surg 2012; 14:704-708.

${ }^{6}$ Carmona P, Mateo E, Casanovas I, Pena JJ, Llagunes J, Aguar F, Andres JD, Errando C. Management of cardiac tamponade after cardiac surgery. J Cardiothorac Vasc Anesth 2012; 26:302-311.

${ }^{7}$ Cruden NL, Morch K, Wong DR, Klinke WP, Ofiesh J, Hilton JD. Clopidogrel loading dose and bleeding outcomes in patients undergoing urgent coronary artery bypass grafting. Am Heart J 2011;161:404-10.

${ }^{8}$ Vieillard-Baron A, Charron C, Chergui K, Peyrouset O, Jardin F. Bedside echocardiographic evaluation of hemodynamics in sepsis: is a qualitative evaluation sufficient? Intensive Care Med 2006;32:1547-52. 
${ }^{9}$ Maltais S, Costello WT, Billings FT 4th, Bick JS, Byrne JG, Ahmad RM, Wagner CE. Episodic monoplane transesophageal echocardiography impacts postoperative management of the cardiac surgery patient. J Cardiothorac Vasc Anesth 2013; 27:665-669. 